\title{
Temporal factors in violence related injuries - An 11 year trend analysis of violence-related injuries from a Swiss Emergency Department
}

\author{
Nicolas Clément, Adrian Businger, Gregor Lindner, Wolfgang P. Müller, J. Hüsler, Heinz Zimmermann, \\ Aristomenis K. Exadaktylos
}

Received: 13 June 2012 / Accepted: 29 October 2012 / Online publiziert: 27 November 2012

(C) Springer-Verlag Wien 2012

Zeitliche Faktoren bei interpersoneller Gewalt Eine 11-Jahres Trendanalyse von Verletzungen durch interpersonelle Gewalt an einem

Schweizerischen Notfallzentrum

\section{Zusammenfassung}

Grundlagen Verletzungen, welche im Rahmen von interpersoneller Gewalt auftreten, stellen ein grosses soziales und medizinisches Problem in den Industriestaaten dar. Nur wenige Daten existieren zu den Charakteristika und der Prävalenz dieser Verletzungen.

Methodik Im Rahmen dieser retrospektiven Analyse wurde die Datenbank des Universitären Notfallzentrums des Inselspitals Bern über einen 11-Jahreszeitraum nach Patienten, welche wegen interpersoneller Gewalt zugewiesen wurden, gescreent. Für alle identifizierten Patienten wurden Daten zum Alter, Herkunftsland, Art der Verletzung und Hospitalisation erhoben. Eine Trend Analyse wurde mittels einer Kendall's tau-b Korrelation errechnet.

Ergebnisse Die Zahl der pro Jahreszeitraum wegen interpersoneller Gewalt zugewiesener Patienten blieb während der Observationsperiode konstant. Patienten mit einem Herkunftsland ausserhalb der Schweiz waren gegenüber Schweizern überrepräsentiert unter Berücksichtigung der demographischen Zusammensetzung des Einzugsgebietes unseres Notfallzentrums. Die Schwere des Verletzungsmusters der Patienten nahm über den Studienzeitraum zu, was in einer Zunahme von Schädelverletzungen Ausdruck fand.

Schlussfolgerungen Obwohl die absolute Zahl wegen interpersoneller Gewalt zugewiesener Patienten

G. Lindner $(\varangle) \cdot$ N. Clément · A. Businger · W. P. Müller ·

H. Zimmermann · A. K. Exadaktylos

Department of Emergency Medicine, Inselspital University

Hospital, 3010 Bern, Switzerland

e-mail: lindner.gregor@gmail.com

J. Hüsler

Department of Mathematical Statistics, University of Bern,

Bern, Switzerland konstant blieb, wurde ein alarmierender Zuwachs an schwerwiegenden Verletzungen, z. B. schwerer SchädelHirn Traumata, über die Zeit verzeichnet.

Schlüsselwörter: Gewalt, Notfall, Trendanalyse

\section{Summary}

Background Injury from interpersonal violence is a major social and medical problem in the industrialized world. Little is known about the trends in prevalence and injury pattern or about the demographic characteristics of the patients involved.

Methods In this retrospective analysis, we screened the database of the Emergency Department of a large university hospital for all patients who were admitted for injuries due to interpersonal violence over an 11 year period. For all patients identified, we gathered data on age, country of origin, quality of injury, and hospitalization or outpatient management. A trend analysis was performed using Kendall's tau-b correlation coefficients for regression analysis.

Results The overall number of patients admitted to our Emergency Department remained stable over the study period. Non-Swiss nationals were overrepresented in comparison to the demographics of the region where the study was conducted. There was a trend toward a more severe pattern of injury, such as an increase in the number of severe head injuries.

Conclusions Although the overall number of patients remained stable over the study period, there was an alarming trend toward a more severe pattern of injury, expressed by an increase in severe head traumas.

Keywords: Violence, Emergency department, Trend analysis 


\section{Introduction}

Interpersonal violence is a national and international problem of growing medical and political interest, which brings a large number of patients to emergency departments [1-4]. Interpersonal violence leads to high costs for a medical system, as many injury patterns require expensive diagnostic workups (e.g. cranial CT-scan) or need to be treated by surgery and require hospitalization $[3,5]$.

A prior study by our group showed a trend to even higher costs due to changes in the injury pattern, with a shift to more severe head injuries over a 6 year period [3].

Crime statistics provided by the federal police department of Switzerland also showed an increase in crimes related to interpersonal violence $[1,2]$. However, these statistics might not reflect the reality encountered in the emergency department. Many victims of interpersonal violence who visit the emergency department (ED) might not report the incident to the police, resulting in an underestimation of real patient numbers. To enable an objective discussion in Switzerland, patient related data from the ED over a long time period is mandatory.

With increasing number of patients with severe violence-related injuries in Switzerland [1-3], exact patient demographics and an analysis of injury patterns might help in developing specific prevention programs for both victims and offenders in interpersonal violence.

Thus, we aimed to analyze the overall trend in prevalence of injuries due to interpersonal violence, the pattern of injury, and the demographic characteristics of patients involved.

\section{Patients, materials and methods}

In this retrospective study, we included all patients admitted to the ED of a large university hospital between January 1, 2000 and December 31, 2010. The emergency unit at the Inselspital, University Hospital Bern, Switzerland, is the only Level 1 accident and emergency unit in this area providing service for all social classes and insurance groups.

All patient data are routinely entered prospectively in our emergency room database software Qualicare (Meierhofer AG, Munich, Germany). All patients visiting our emergency department during the period of the study were automatically scanned for the standardized keyword "Schlägerei" (Engl. brawl), which is used by our triage staff for interpersonal violence-related injuries. Data on sex, age, nationality, cause of admittance, time and date of admittance, location and pattern of injury were collected and analyzed for each year.

Continuous data with a normal distribution were expressed as mean and standard deviation or as median and range, and dichotomous data were presented as frequencies and percentages. Data were analysed using Student's $t$ test when normally distributed and the MannWhitney $U$ test when not normally distributed. Dichoto-

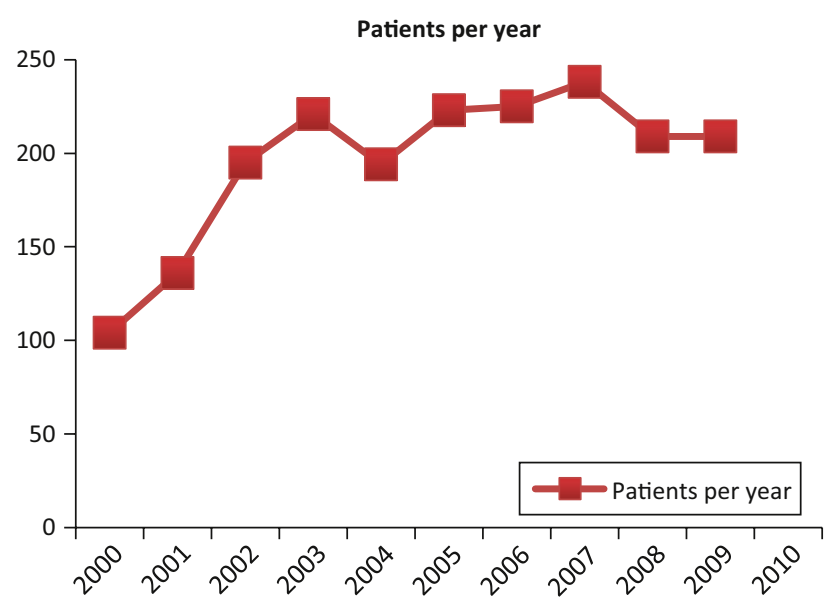

Fig. 1 Number of patients per year admitted due to interpersonal violence-related injuries

mous variables were analyzed by the $\chi^{2}$ test or Fisher's exact test. Trend analysis was performed using Kendall's tau-b correlation coefficients for regression analysis. A 2 -sided $p<0.050$ was considered statistically significant. All statistical analyses were performed using SPSS $^{\circledR} 17.0$ (SPSS; Chicago, Illinois, USA).

\section{Results}

During the study period, 1,963 male (92\%) and 170 female patients $(8 \%)$ were admitted due to interpersonal violence (total of 2,133 patients). Men remained strongly overrepresented during the study period. There was no significant increase in overall patient numbers over an 11 year period $(p=0.1646)$. Figure 1 shows the trend of patient admissions due to interpersonal violence-related injuries over time.

The median age was 26 years for male patients (range 12-82 years) and 29 years for female patients (range $15-68$ years). There were no significant changes in the age of patients over an 11 year period ( $p=0.3948)$.

Of all patients, 1,352 (63.4\%) were Swiss nationals, 166 (7.8\%) from African countries, $155(7.3 \%)$ from countries of the European Union, 152 (7.1\%) from Balkan, and 308 (14.4\%) from other countries.

Non-Swiss nations were overrepresented compared to the population in Bern (36\% versus $22.1 \%$ in the Canton of Bern; Fig. 2).

Two thirds of patients were employed or were students or trainees (66.9\%).Most patients stayed less than 24 hours (outpatient treatment); $11.9 \%$ of patients needed in-hospital treatment. We saw a significant trend of increasing number of patients needing hospitalization $(p<0.02)$, although the overall absolute number remains very low compared to outpatient treatment (253 versus 1,704 patients).

There was a significant shift to more patients being admitted to the ED on weekend days compared to weekdays ( $p$ for trend $<0.001$ ) during this 11 year period. The increase in weekend consultations was seen in both 


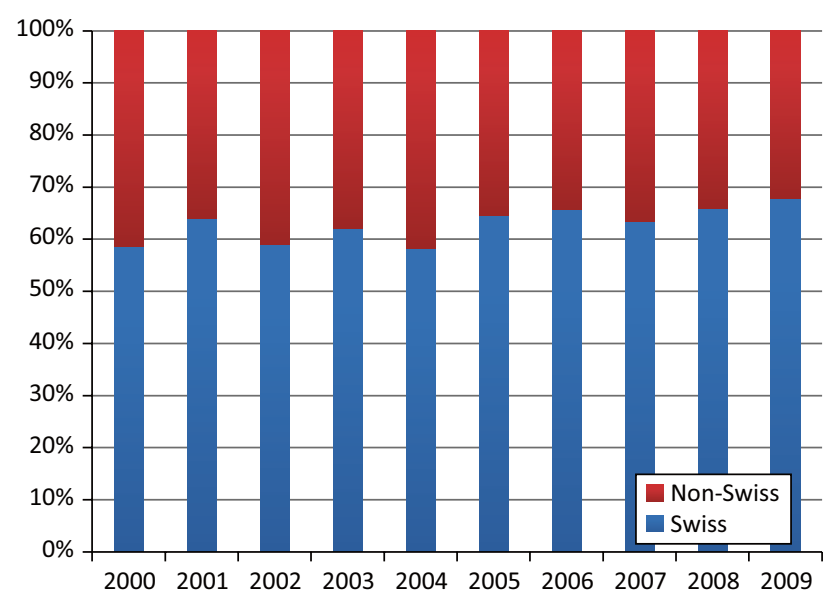

Fig. 2 Relation between Swiss and non-Swiss patients admitted due to interpersonal violence-related injuries

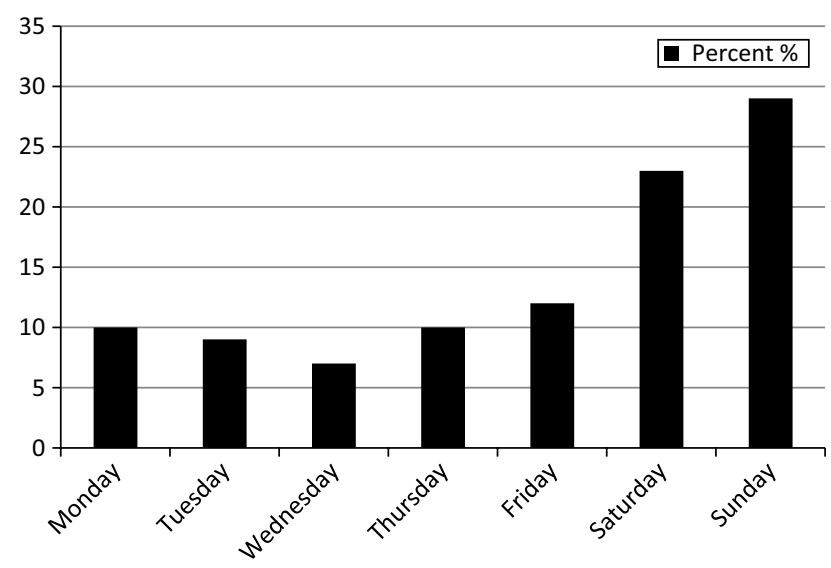

Fig. 3 Admissions per weekday for interpersonal violencerelated injuries

Swiss ( $p$ for trend $<0.01$ ) and non-Swiss patients ( $p$ for trend $<0.05$ ) equally. An overview of admissions per weekday for the whole study period is given in Fig. 3.

Most commonly, the injury pattern was limited to isolated head injuries, accounting for $66.1 \%$ of all injuries. Isolated injuries of the upper extremity $(9.7 \%)$ and to the trunk (6.1\%) were less common. A combination of injuries to different body areas was seen in $14 \%$ of patients (e.g. head and trunk or upper and lower extremity, etc; Fig. 4).

Most injury patterns remained constant over the investigated 11 year period. Maxillofacial fractures (increase from 17 patients in year 2000 to 57 patients per year in 2010) and head injuries (increase from 71 patients in year 2000 to 175 patients per year in 2010) though showed an increase during this period.

\section{Discussion}

In the present study, we showed that, it appears that there is no overall increase in interpersonal violence, but serious injuries such as head trauma increased. Foreign patients remained strongly overrepresented and many

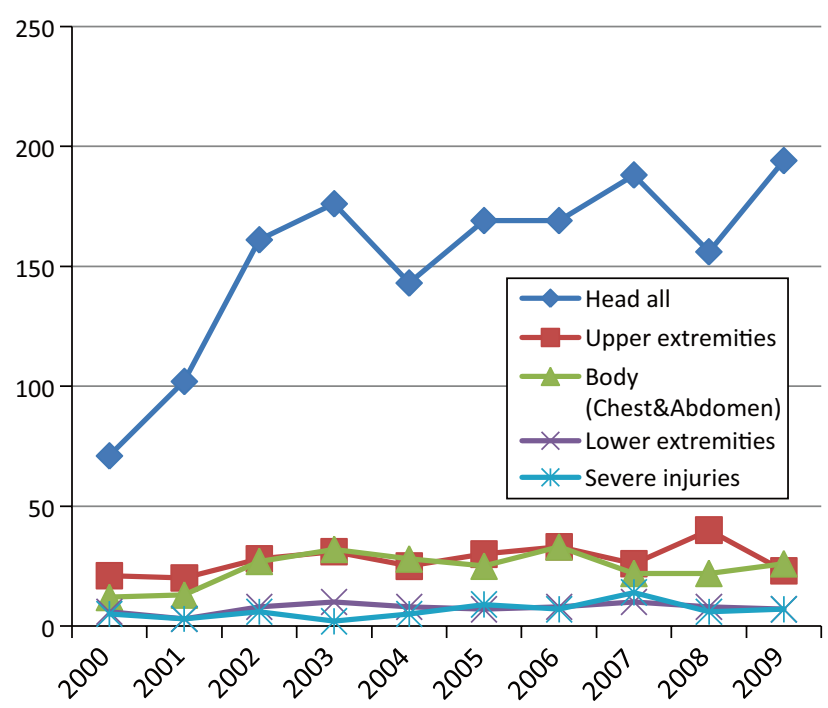

Fig. 4 Trend in patterns of injury over the study period

patients admitted due to interpersonal violence are unemployed.

The finding of a stable patient number admitted to the ED due to interpersonal violence in the present study confirms results from a similar analysis from England and Wales [6]. However, findings of the same group from a later study period even showed a small decrease in violence [7].

We found that there was a trend toward admission due to interpersonal violence on Saturdays and Sundays, which also confirms data from a previous study from the United Kingdom [8]. This finding was also confirms data from Howe and coworkers who also found their interpersonal violence-related admissions to be mainly on the weekend with most of the patients being in their twenties [9]. Together with findings that interpersonal violencerelated admissions to the ED are related to alcohol prices, the current findings suggest that there is an international trend toward weekend alcohol consumption triggering aggression and interpersonal violence [10].

Even more alarming are the findings that the injury pattern changed to more severe traumas, as supported by the increasing number of serious head injuries. These findings support previous data from our center [3]. The increasing rate of serious head injuries may also be an explanation for the higher rate of hospitalizations seen over the study period.

Moreover, we found that, compared to the general unemployment rate in Switzerland, the rate among patients admitted due to interpersonal violence-related injuries is very high.

The reasons might be found in the lower social status due to a lower educational level and lower income in foreign nationals. However, the problem is not new: Dimond in his work discussed the problems of interpersonal violence-related injuries in the emergency room and the legal position of the staff already in 1994 [11]. Political efforts toward better socioeconomic integration of foreign nationals living in Switzerland might be the key point in prevention of interpersonal violence. 
A distinction between offenders and victims among our patients was not possible in this study. An earlier pilot study by Exadaktylos et al. showed that it is very difficult to identify who is a victim in the ED, as patients tend to see themselves as a victim anyway, at least when asked in the ED [3]. To develop a more specific prevention program for offenders and victims separately, more studies are needed dealing with the question of how to identify possible victims and offenders. Therefore, further studies in cooperation with police departments or other legal authorities should be encouraged. Gender, age, and nationality specific intervention programs for prevention of interpersonal violence are also mandatory.

Our study is limited by its retrospective design. Additionally, we cannot exclude the possibility that some patients with injuries due to interpersonal violence were not identified in the present study, since some patients presenting to the ED will conceal the true circumstances of their injury.

In conclusion, there is a trend toward weekend days for admissions of patients due to interpersonal violence-related injuries. We found an alarming pattern of injuries, with an increasing number of severe head traumas over time, while the overall number of patients treated remained stable.

\section{Conflict of interest}

The authors have no conflicts of interest to disclose.

\section{References}

1. Bern K. Kriminalstatistik des Kantons Bern. 2011. http:// www.police.be.ch/police/de/index/medien/medien/ statistik/Kriminalstatistik.html. Accessed March 2012.
2. Statistik Bf. Kriminalstatistik der Schweiz. 2011. http://www. bfs.admin.ch/bfs/portal/de/index/themen/19/03/02/ key/01.html. Accessed March 2012.

3. Exadaktylos AK, Hauselmann S, Zimmermann H. Are times getting tougher? A six year survey of urban violence related injuries in a Swiss university hospital. Swiss Med Wkly. 2007;137:525-30.

4. Exadaktylos A, Jonas C, Eggli S, Kohler HP, Zimmermann H. Violence in Bern. Swiss Med Wkly. 2001;131:527.

5. Knapp R. The impact of interpersonal violence on health care. Nurs Clin North Am. 2011;46:465-70, vii.

6. Sivarajasingam V, Shepherd J, Matthews K, Jones S. Trends in violence in England and Wales 1995-2000: an accident and emergency perspective. J Public Health Med. 2002;24:219-26.

7. Sivarajasingam V, Morgan P, Matthews K, Shepherd J, Walker R. Trends in violence in England and Wales 20002004: an accident and emergency perspective. Injury. 2009;40:820-5.

8. Sivarajasingam V, Corcoran J, Jones D, Ware A, Shepherd J. Relations between violence, calendar events and ambient conditions. Injury. 2004;35:467-73.

9. Howe A, Crilly M. Violence in the community: a health service view from a UK Accident and Emergency Department. Public Health. 2002;116:15-21.

10. Sivarajasingam V, Matthews K, Shepherd J. Price of beer and violence-related injury in England and Wales. Injury. 2006;37:388-94.

11. Dimond B. Violence in the accident and emergency department. Accid Emerg Nurs. 1994;2:172-6. 